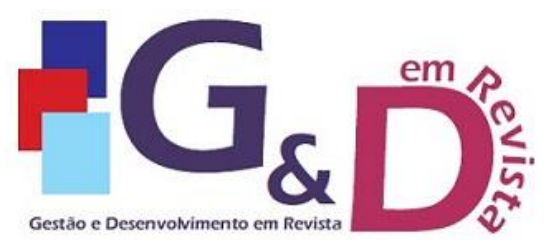

\title{
AVALIAÇÃO DA VIABILIDADE DA IMPLANTAÇÃO DO CONTRATO FUTURO DE FEIJÃO COMUM NO BRASIL ${ }^{1}$
}

Tatiana Borges da Silva

Mestranda pelo Programa de pós-graduação em Economia da Universidade Estadual de Maringá (PCE/UEM). E-mail: tatianaborgesdasilva@outlook.com

Renan Henrique Luquini

Mestre em Economia Regional pela Universidade Estadual de Londrina - UEL. Atualmente é Professor Programa de Pós-Graduação em Economia Empresarial da UEL.

E-mail: rhluquini@gmail.com

\section{Alexandre Florindo Alves}

Doutor em Economia Aplicada pela Escola Superior de Agricultura Luiz de Queiroz. Atualmente é Professor Associado do Departamento de Economia da Universidade Estadual de Maringá - UEM. E-mail: afalves@uem.br

\section{Julyerme Matheus Tonin}

Doutor em Economia Aplicada pela Escola Superior de Agricultura Luiz de Queiroz. Atualmente é Professor Associado do Departamento de Economia da Universidade Estadual de Maringá - UEM. E-mail: jmtonin@uem.br

\section{RESUMO}

O presente artigo tem como objetivo estudar o mercado de feijão brasileiro com a finalidade de avaliar a viabilidade de implantação de um contrato futuro de feijão comum no Brasil. Para verificar quais fatores afetam a viabilidade, foi utilizada a Teoria do Sucesso ou Fracasso de Contratos Futuros de Pennings e Leuthold (1999), enfocando na abordagem macro desta teoria. Os dados utilizados no trabalho são obtidos a partir da base de dados da FAOSTAT, IBGE, CONAB e CEPEA. Analisando a característica do produto e do mercado, os resultados mostram que dos oito aspectos analisados, quatro apresentam situações favoráveis (volatilidade de preços, tamanho do mercado físico, grau de concentração do mercado e integração vertical) e quatro desfavoráveis (perecibilidade e possibilidade de estocagem, homogeneidade e capacidade de mensuração, formas de comercialização e intervenção governamental). Portanto, de acordo com os resultados encontrados na abordagem macro não é possível uma implementação de um contrato futuro de feijão comum no Brasil.

Palavras-chave. Feijão Comum; Contrato Futuro; Viabilidade

\section{ABSTRACT}

This paper aims to study the brazilian bean market in order to assess the feasibility of implementing a common bean futures contract in Brazil. To verify which factors affect viability, Pennings and Leuthold's Theory of Success or Failure of Future Contracts was used, focusing on the macro approach of this theory. The data used in the study are obtained from the database of FAOStat, IBGE, CONAB and CEPEA. Analyzing the characteristics of the product and the market, the results show that of the eight aspects analyzed, four present favorable (price volatility, physical market size, degree of market concentration and vertical integration) and four unfavorable situations (perishability and possibility of storage, homogeneity and measurement capacity, forms of commercialization and government intervention). Therefore, according to the results found in the macro approach, it is not possible to implement a common bean futures contract in Brazil.

Keywords. Common Beans; Future Contract; Viability;

\footnotetext{
${ }^{1}$ Artigo apresentado no IX Congresso Nacional de Pesquisa em Ciências Sociais Aplicadas - Conape e publicado nos anais do respectivo Congresso e aprovado para publicação nessa Revista pelo sistema Fast-Track.
} 


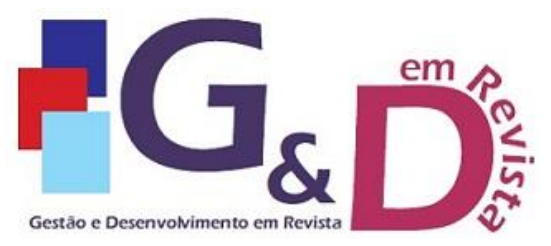

Gestão e Desenvolvimento em Revista

V. 8, N. 2, jul-dez/2021, p. 22-41.

ISSN online: $2446-8738$

Artigo recebido em: 08/11/2021

Artigo aprovado em: 08/12/2021

\section{INTRODUÇÃO}

O feijão é um típico produto da alimentação brasileira que é cultivado por pequenos e grandes produtores em todas as regiões, sendo um dos alimentos mais antigos do mundo. Além do papel relevante na alimentação, o feijão é um dos produtos agrícolas de grande importância econômico-social, devido principalmente à mão-de-obra empregada durante o ciclo da cultura (DALCHIAVON et al., 2011).

O mercado do feijão é influenciado pelo tipo de grão comercializado, fatores agronômicos e sazonalidade. $\mathrm{O}$ preço depende principalmente do mercado interno, tendo em vista que grande parte da produção é consumida nacionalmente. A existência de três safras da cultura facilita a mudança na intenção de plantio, pelo produtor, ao longo do ano, podendo influenciar os preços. Uma praça importante na formação destes é o mercado atacadista de São Paulo e, no Nordeste, a de Barreiras-BA (COÊLHO, 2019).

Uma das possibilidades de mitigar o risco de preços é por meio da utilização de contratos futuros. Um contrato futuro é um compromisso assumido entre duas partes de comprar ou vender um ativo numa determinada data e preço. Eles são um importante instrumento financeiro, uma vez que permite que sejam negociados hoje, direitos futuros em condições de incerteza (CVM, 2021).

Dessa forma, o objetivo do presente artigo é analisar a viabilidade da implantação de um contrato de feijão para garantir melhor previsibilidade para o produtor no Brasil. $\mathrm{O}$ produto utilizado será o feijão comum, pois ele corresponde a maior parte da produção total. O estudo se justifica uma vez que não há contratos futuros de feijão na bolsa de mercadorias e nem trabalhos analisando este fator.

\section{REFERENCIAL TEÓRICO E ANALITICO}

Muitos contratos futuros de commodities agropecuárias são lançados ao redor do mundo e fracassam em pouco tempo (COSTA, 2008). Segundo Brorsen e Fofana (2001) no período de 1994 a 1998 foram lançados 140 contratos e desse total 58\% fracassaram antes de completar 3 anos, o que indica que a introdução de um contrato futuro em uma economia é um processo complexo.

Pennings e Leuthold (1999) classificaram como macro e micro os determinantes da viabilidade dos contratos futuros, por sua vez, neste trabalho será utilizado a abordagem macro como metodologia, que leva em conta os fatores não subjetivos ou os conjuntos de atributos físicos que a commodities deve possuir para um possível sucesso deste contrato futuro. Dentre os trabalhos que utilizaram essa metodologia pode-se destacar Santos (2001), Siqueira (2003) e Costa (2008).

As variáveis tidas como importantes nessa metodologia para a determinação de um novo contrato futuro serão descritas no decorrer deste tópico, os dados serão retirados das bases da FAOSTAT, IBGE, CONAB e CEPEA, utilizando 2010 como ano de partida da análise.

\section{a) Perecibilidade e possibilidade de estocagem}

Para o comércio de commodities agropecuárias, a perecibilidade e possibilidade de estocagem são importantes pois auxiliam o produtor escolher o momento de venda do seu produto de forma a maximizar o seu negócio, além de proteger contra os riscos e incertezas do mercado (SILVA, 2012).

A Teoria da Estocagem foi inicialmente estudada por Kaldor (1939); Working (1949) e Brennan (1958), a premissa é que o detentor da mercadoria física tem o poder de retê-la 


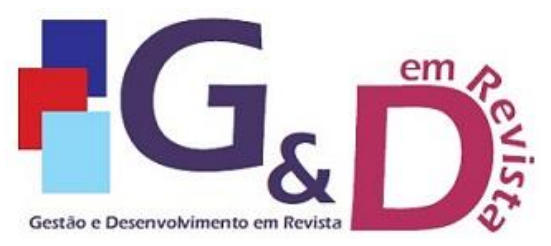

Gestão e Desenvolvimento em Revista

V. 8, N. 2, jul-dez/2021, p. 22-41.

ISSN online: $2446-8738$

Artigo recebido em: 08/11/2021

Artigo aprovado em: 08/12/2021

quando o preço do mercado à vista está abaixo do esperado e vendê-la quando o preço estiver a seu favor. Os autores ainda afirmaram que a estratégia de estocagem é positiva quando a receita marginal entre o preço futuro esperado no momento da venda/entrega e o preço à vista no momento da colheita é maior do que os custos de estocagem incorridos. Segundo Santos (2001), essa premissa é um dos determinantes do sucesso ou fracasso dos contratos futuros.

Além disso, cabe destacar que com o avanço nas tecnologias de armazenagem, é possível estocar commodities com maiores níveis de perecibilidade. Outro avanço importante, ocorreu com a flexibilização criada pela liquidação financeira dos contratos futuros (BLACK, 1986; SIQUEIRA, 2003).

\section{b) Homogeneidade e capacidade de mensuração}

Para se comercializar a futuro, é necessário que o produto esteja padronizado considerando o tamanho, a qualidade física, a tipificação, entre outros fatores relativos à commodity. Para Brorsen e Fofana (1995) a homogeneidade significa a efetividade do sistema de medida. Pode-se considerar efetivo um sistema no qual as medidas explicam adequadamente as diferenças qualitativas de valor entre as variedades de commodities. Se a commodity não tem um sistema de medida efetivo, tornando-se difícil estabelecer um padrão de entrega.

Para Vieira et al. (2008), a homogeneidade dos produtos, a transparência, a velocidade das informações e a livre mobilidade de recursos permitem que os preços se ajustem conforme as leis de mercado, ou seja, de acordo com as pressões de oferta e procura. A B3 adota critérios de padronização do bem a ser transacionado, como por exemplo o nível máximo de impurezas. No Brasil a classificação oficial do feijão é feita pelo Ministério de Agricultura, Pecuária e Abastecimento (MAPA) por meio da normativa 12/2008, que fornece informações importantes sobre as características, qualidade e nível de impureza, itens importantes para o design do contrato.

\section{c) Tamanho do mercado}

Segundo Santos e Aguiar (2003), quanto maior o tamanho do mercado físico (produção e estoque) e disponível (volume disponível), maior a possibilidade de um mercado futuro ser bem-sucedido. Para Black (1986), quando há um grande mercado físico, existe a dificuldade de estruturas dominarem o mercado, ou seja, a commodity não aparenta ter grande interesse comercial, pois os poucos participantes não conseguem ditar preços, o que pode atrair hedgers para o mercado futuro.

Será analisado o valor bruto da produção, a produção total em toneladas, bem como a importação, exportação, área plantada, e produtividade para avaliar o tamanho do mercado físico de feijão, conforme sugerido por Costa (2008).

\section{d) Grau de concentração no mercado}

Conforme Cunha (2000), os aspectos centrais de qualquer mercado estão na sua organização, concentração e concorrência. Segundo Santos (2001), a aproximação do mercado do conceito teórico de concorrência perfeita é importante pois falhas de mercado tal como monopólios e cartéis podem alterar os preços e a oferta da commodity, atrapalhando a implantação do mercado futuro da referida commodity.

Em um mercado concentrado, dominado por poucos agentes, há distorções, dado que esses agentes exercem influência direta nos preços, reduzindo a eficiência dos mecanismos criados para gerir os riscos de preços. Então é possível afirmar que quanto mais competitiva uma cadeia agroindustrial, maior a chance de sucesso do contrato futuro (MARQUES; 


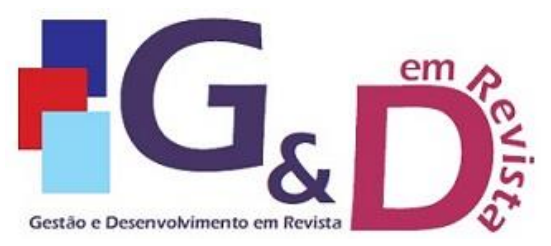

Gestão e Desenvolvimento em Revista

V. 8, N. 2, jul-dez/2021, p. 22-41.

ISSN online: $2446-8738$

Artigo recebido em: 08/11/2021

Artigo aprovado em: 08/12/2021

MELLO; MARTINES, 2006). Nesse contexto, a competição do mercado de feijão analisando a participação de cada cidade e estado na produção total.

\section{e) Intervenção governamental}

O mercado deve ser livre e competitivo para um contrato futuro ser bem-sucedido, então, deve-se haver ausência de forças controladoras como cartéis, intervenção governamental ou imperfeições do mercado. A intervenção do governo é entendida como barreira para o desenvolvimento de um mercado futuro de feijão no Brasil pois o estado poderia alterar as regras de comercialização gerando insegurança aos participantes do mercado (SIQUEIRA, 2003; SOUZA, 1996).

O governo também pode oferecer proteção aos produtores utilizando os subsídios e os preços mínimos como ferramentas, o que acabaria por desestimular a procura por outras fontes de gerenciamento de risco de preços. Neste trabalho as intervenções governamentais no setor feijoeiro serão avaliadas pela influência do governo na precificação, regulamentação, subsídios, políticas de preços mínimos e outras intervenções.

\section{f) Formas de comercialização}

Para a transferência do risco são utilizados os mercados futuros e a termo. O mercado a termo tem sido uma alternativa viável, na qual as especificidades e a entrega física do produto assumem papéis importantes nas transações. Porém, há o risco dos participantes não cumprirem o contrato, já que os contratos são específicos, realizados sem intermediação (SANTOS, 2001).

A presença de contratos a termo e outras relações contratuais pode competir com o contrato futuro do feijão, o que pode inviabilizar este contrato. Com isso, é analisado as relações de compra e venda verificando a existência contratos a termo e outras relações contratuais que possam exercer influência na viabilidade do contrato futuro de feijão.

\section{g) Volatilidade}

A Volatilidade pode ser definida como uma medida estatística de disseminação do retorno de um título, ou mesmo de um índice de mercado (LIRA; ALMEIDA, 2020). Segundo Jubert et all. (2008), a volatilidade de um ativo representa as alterações ocorridas nos seus preços em razão de diversos fatores relacionados ao desempenho da empresa emitente e da conjuntura econômica. Ela é considerada como a mais importante característica na determinação do sucesso de um sistema de comercialização a futuro.

Muita incerteza nos preços dos mercados físicos e futuro pode ser causada devido a grandes flutuações de preço nos mercados. Os participantes do mercado sentirão estimulados ao hedge para se proteger da variação dos preços e a especulações para obter lucro com a oscilação dos preços. Para Siqueira (2003), as commodities que não apresentam volatilidade não indicam riscos que seja necessário a realização de mecanismos de gerenciamento dos preços, consequentemente não estimulam a realização de hedge

Neste trabalho, será feita uma comparação entre a volatilidade dos preços do feijão e commodities negociadas na BM\&F. O cálculo da volatilidade utilizado será o descrito em Purcell e Koontz (1999), como apresentado na equação abaixo:

$$
\sigma=\sqrt{\frac{\sum_{t=1}^{n}\left(\ln \left(\frac{P_{t}}{P_{t-1}}\right)-\mu\right)^{2}}{n-1}} \cdot m
$$




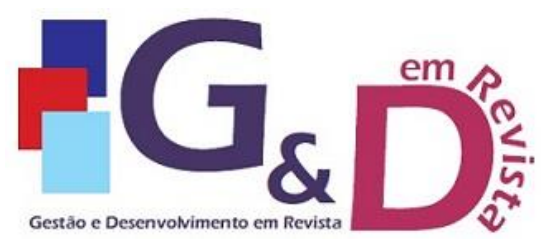

Gestão e Desenvolvimento em Revista

V. 8, N. 2, jul-dez/2021, p. 22-41.

ISSN online: $2446-8738$

Artigo recebido em: 08/11/2021

Artigo aprovado em: 08/12/2021

em que o $\sigma$ é desvio-padrão ou volatilidade, $\mathrm{P}_{\mathrm{t}}$ é preço mensal do ativo no período corrente, $\mathrm{P}_{\mathrm{t} 1} \mathrm{o}$ preço mensal do ativo no período anterior, $\mu$ é média das mudanças percentuais no preço do ativo, n o número de observações e m é o número de meses no ano.

\section{h) Integração Vertical}

Porter (1986) definiu integração vertical como sendo o agrupamento de vários processos de produção, distribuição, vendas ou outros processos tecnologicamente distintos dentro de uma mesma empresa. Outras definições do autor apontam para o fato de uma empresa agregar diversas fases de sua cadeia produtiva, aumentando assim o número de produtos ou processos intermediários para uso próprio.

Grant (2002) afirmou que quanto maior a propriedade e controle de uma empresa sobre os estágios sucessivos da cadeia de valor de seus produtos, maior o grau de integração vertical. Essa estratégia pode ocorrer em 2 direções: para frente, integrando as fases de distribuição dos produtos e serviços, ou para trás, controlando o fornecimento de bens e matérias-primas.

Segundo Costa (2008), o êxito de um contrato futuro está negativamente correlacionado com o grau de integração vertical, visto que reduz o risco de preços para os agentes e também o nível de concorrência do mercado à vista, desta forma ocorre a redução da demanda pelos instrumentos de gestão de risco de mercado. Sendo assim, neste trabalho a integração vertical no setor feijoeiro será analisada com o auxílio do censo agropecuário disponibilizado pelo IBGE.

\subsection{DESIGN DO CONTRATO}

Após a abordagem macro, é possível sugerir um design do contrato futuro de feijão (caso seja viável) adequado às necessidades e exigências do mercado brasileiro, de modo que os contratos futuros se apresentem como substitutos das negociações no mercado físico. $\mathrm{O}$ desenho deve atrair os hedgers (BLACK, 1986).

Segundo Hull (2005), as informações que devem estar contidas no contrato são: variedade da commodity negociada, local e data de entrega, tipo de liquidação, tamanho do contrato, número de meses do ano em que há negociações, unidades de cotação dos preços, limites máximos e mínimos diários de movimentação de preços, horas de negociação, margens requeridas, tamanho das posições relatadas e limite das posições para traders individuais.

\section{RESULTADOS E DISCUSSSÕES}

Este tópico apresenta os resultados encontrados na análise macro, os dados utilizados baseiam-se em diversas fontes da cadeia produtiva do feijão.

\section{a) Perecibilidade e possibilidade de estocagem}

Segundo Cláudio Bragantini (2005) o prejuízo anual que a economia mundial sofre em consequência das perdas pós-colheita é grande. A causa mais frequente de perdas no armazenamento é o ataque de insetos, fungos e roedores. Ocorrem ainda perdas das qualidades intrínsecas como a aparência e o sabor, no caso do feijão para consumo.

O feijão pode ser armazenado a granel, em sacos de aniagem, de polipropileno ou de plástico, e em silos especialmente construídos para este fim. Quando o armazenamento se destina a curtos períodos o teor de umidade de $15 \%$ garante a boa qualidade do produto. Caso 
haja necessidade de estocagem mais prolongada, recomenda-se reduzir a umidade para $12 \%$. Se os grãos forem armazenados em sacos plásticos ou recipientes vedados, a umidade deve ser inferior a $10 \%$ (PELOSO E SILVA, 2006).

A média diária de temperatura para um bom armazenamento situa-se entre $20^{\circ} \mathrm{C}$ e $25^{\circ} \mathrm{C}$, e umidade relativa média de $75 \%$ (BIAVI et al., 2003). O prazo de estocagem do feijão é de até 12 meses. Ao término desse prazo pode ocorrer alterações na cor e tegumento, perca do valor nutritivo e endurecimento do grão (FONSECA, 2020). Assim, apesar do feijão não ser considerado um produto perecível, não possui um grande período de estocagem. Então, para minimizar a perda de qualidade, é preciso armazenar o feijão em um espaço em que a umidade relativa e temperatura ambiente estejam dentro dos padrões, além de controlar insetos e roedores. Entretanto, a capacidade de estocagem e a perecibilidade parecem não ser um empecilho para o sucesso de um contrato futuro de feijão.

\section{b) Homogeneidade e capacidade de mensuração}

O feijão embalado e classificado deve apresentar-se homogêneo quanto às suas especificações de qualidade, apresentação e identificação. Para que haja um padrão e garantia de qualidade do grão a ser comercializado, o MAPA criou a Instrução Normativa 12/2008 estabelecendo um Regulamento Técnico do Feijão definindo sua classificação oficial. O MAPA (2008) considera como feijão o grão oriundo das espécies Phaseolus vulgaris L. e Vigna unguiculata $(L)$ Walp, sendo assim divididos em dois grupos, Feijão-Comum (Grupo I), Feijão-Caupi (Grupo II), estando classificados conforme a tabela a seguir como Tipo 1 (Branco), Tipo 2 (Preto), Tipo 3 (Cores) e Fora de Tipo (grãos misturados que não atendem as porcentagens mínimas para se enquadrar nas classificações anteriores).

Tabela 1 - Tolerância de defeitos em \% por enquadramento/classificação

\begin{tabular}{|c|c|c|c|c|c|}
\hline \multirow{3}{*}{$\begin{array}{l}\text { Enquadramento } \\
\text { do produto }\end{array}$} & \multicolumn{4}{|c|}{ Defeitos Graves } & \multirow{3}{*}{$\begin{array}{c}\text { Total de Defeitos } \\
\text { Leves }\end{array}$} \\
\hline & \multicolumn{2}{|c|}{ Matérias Estranhas e Impurezas } & \multirow{2}{*}{$\begin{array}{c}\text { Total de } \\
\text { mofados, } \\
\text { ardidos, e } \\
\text { germinados }\end{array}$} & \multirow{2}{*}{$\begin{array}{c}\text { Total de } \\
\text { Carunchados } \\
\text { e atacados por } \\
\text { lagartas }\end{array}$} & \\
\hline & Total & $\begin{array}{c}\text { Insetos Mortos } \\
(*)\end{array}$ & & & \\
\hline Tipo 1 & 0 à $0,5 \%$ & 0 à $0,1 \%$ & 0 à $1,5 \%$ & 0 à $1,5 \%$ & 0 à $2,5 \%$ \\
\hline Tipo 2 & $>0,5 \%$ à $1 \%$ & $>0,1 \%$ à $0,2 \%$ & $>1,5 \%$ à $3 \%$ & $>1,5 \%$ à $3 \%$ & $>2,5 \%$ à $6,5 \%$ \\
\hline Tipo 3 & $>1 \%$ à $2 \%$ & $>0,2 \%$ à $0,3 \%$ & $>3 \%$ à $6 \%$ & $>3 \%$ à $6 \%$ & $>6,5 \%$ à $16 \%$ \\
\hline Fora do tipo & $>2 \%$ à $4 \%$ & $>0,3 \%$ à $0,6 \%$ & $>6 \%$ à $12 \%$ & $>6 \%$ à $12 \%$ & $>16 \%$ \\
\hline Desclassificado & $>4 \%$ & $>0,6 \%$ & $>12 \%$ & $>12 \%$ & - \\
\hline
\end{tabular}

(*)\% máximo de insetos mortos permitidos, dentro do total de Matérias Estranhas e Impurezas.

Fonte: Elaboração própria com base em dados da Instrução Normativa 12/2008 (2021).

Porém, dentro de cada classificação há vários tipos de feijão, mostrando que não há homogeneidade do produto de forma agregada. É valido destacar que dentre os diversos tipos de grãos do feijoeiro-comum, merece destaque o tipo carioca, que representa quase $70 \%$ do mercado consumidor brasileiro c(DEL PELOSO E MELO, 2005).

\section{c) Tamanho do mercado}

O tamanho do mercado físico do feijão possui diversas formas de serem medidas, como a produção cereal e o fluxo comercial com outros países. No Brasil, o feijão do tipo carioca é o mais produzido (63\% do total), seguido do feijão-de-corda (19\%) e do feijão preto $(18 \%)$. A produção do feijão carioca está distribuída uniformemente entre as três safras. O feijão preto tem produção concentrada na primeira safra, com $67 \%$ do total, $24 \%$ na segunda safra e $9 \%$ na terceira safra. Por outro lado, o feijão-de-corda é mais produzido na segunda 
safra ( $89 \%$ do total). Estima-se que em torno de $45 \%$ a $55 \%$ da produção total de feijão ocorra na $1^{\text {a }}$ safra, $20 \%$ a $35 \%$ na $2^{\text {a }}$ safra e $10 \%$ a $20 \%$ na $3^{\text {a }}$ (DURIGNON et. all, 2015).

É possível identificar que o Nordeste é a região com maior área cultivada de feijão no período analisado, sendo seguido pela região Sul, e tendo o Norte como a região com menor área produzida (Tabela 2). Mesmo em destaque, o Nordeste seguiu a tendência no decorrer dos anos de reduzir sua área plantada de forma considerável, o mesmo ocorreu com as demais regiões, exceto o Centro-Oeste. Na safra 2010/11 o Brasil possuía 3.990 mil hectares para o cultivo do feijão, enquanto para a Safra 2019/20 a área foi de apenas 2.927 mil hectares, demonstrando a redução ocorrida no Brasil, principalmente entre os anos 2010 e 2012.

Tabela 2 - Área plantada de feijão em mil hectares

\begin{tabular}{|c|c|c|c|c|c|c|c|c|c|c|}
\hline Região/Safra & $2010 / 11$ & $2011 / 12$ & 2012/13 & $2013 / 14$ & $2014 / 15$ & $2015 / 16$ & 2016/17 & $2017 / 18$ & 2018/19 & $2019 / 20$ \\
\hline Norte & 149 & 158 & 133 & 102 & 88 & 92 & 113 & 98 & 88 & 78 \\
\hline Nordeste & 2174 & 1504 & 1400 & 1642 & 1550 & 1413 & 1546 & 1601 & 1457 & 1511 \\
\hline Centro-Oeste & 357 & 342 & 356 & 468 & 421 & 387 & 475 & 483 & 402 & 402 \\
\hline Sudeste & 592 & 608 & 558 & 488 & 431 & 425 & 468 & 460 & 464 & 444 \\
\hline Sul & 719 & 650 & 628 & 666 & 534 & 521 & 578 & 529 & 511 & 491 \\
\hline Total & 3990 & 3262 & 3075 & 3366 & 3024 & 2837 & 3180 & 3172 & 2922 & 2927 \\
\hline
\end{tabular}

Fonte: Elaboração própria com base nos dados da Conab (2021).

Para a Safra 2019/20 a região Nordeste possuía a maior produção e o Norte a menor, sendo consecutivamente elas de 859.000 e 76.000 toneladas como pode ser visto na tabela 2 .

Tabela 3 - Produção em mil toneladas

\begin{tabular}{|c|c|c|c|c|c|c|c|c|c|c|}
\hline $\begin{array}{c}\text { Região/Safr } \\
\mathbf{a} \\
\end{array}$ & $\begin{array}{c}2010 / \\
11\end{array}$ & $2011 / 12$ & $\begin{array}{c}2012 / 1 \\
3 \\
\end{array}$ & $\begin{array}{c}2013 / 1 \\
4 \\
\end{array}$ & $\begin{array}{c}2014 / 1 \\
5 \\
\end{array}$ & $\begin{array}{c}2015 / 1 \\
6 \\
\end{array}$ & $\begin{array}{c}2016 / 1 \\
7 \\
\end{array}$ & $2017 / 18$ & $\begin{array}{c}2018 / 1 \\
9 \\
\end{array}$ & $\begin{array}{c}2019 / 2 \\
0 \\
\end{array}$ \\
\hline Norte & 142 & 124 & 105 & 78 & 71 & 77 & 131 & 78 & 80 & 76 \\
\hline Nordeste & 961 & 289 & 425 & 674 & 644 & 338 & 679 & 641 & 656 & 859 \\
\hline Centro-Oeste & 576 & 603 & 583 & 873 & 838 & 559 & 837 & 791 & 712 & 774 \\
\hline Sudeste & 949 & 1013 & 816 & 773 & 707 & 710 & 811 & 783 & 756 & 753 \\
\hline Sul & 1106 & 889 & 878 & 1056 & 950 & 829 & 943 & 822 & 814 & 760 \\
\hline Total & 3733 & 2918 & 2806 & 3454 & 3210 & 2513 & 3400 & 3116 & 3018 & 3222 \\
\hline
\end{tabular}

Fonte: Elaboração própria com base nos dados da Conab (2021).

$\mathrm{Na}$ Tabela 4, encontra-se o valor bruto da produção (VBP) dos sete maiores produtos agrícolas brasileiros nos anos de 2017 e 2018, onde é possível verificar a importância da produção de feijão para o mercado brasileiro. Em 2018, verifica-se que o feijão foi o $7^{\circ}$ produto agrícola quando se fala em valor bruto da produção, atingindo cerca de 2,7 bilhões de dólares. Isso mostra que o tamanho físico do mercado brasileiro é grande o suficiente para comportar um mercado futuro dessa mercadoria. 


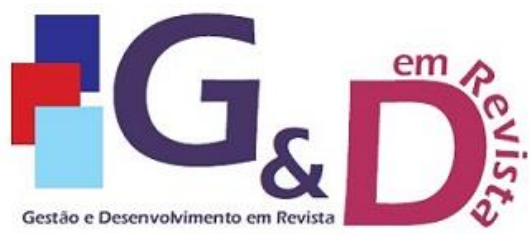

Gestão e Desenvolvimento em Revista

V. 8, N. 2, jul-dez/2021, p. 22-41.

ISSN online: $2446-8738$

Artigo recebido em: 08/11/2021

Artigo aprovado em: 08/12/2021

Tabela 4 - VBP dos sete maiores produtos agrícolas brasileiros (em milhões de dólares)

\begin{tabular}{ccc}
\multirow{2}{*}{ Produtos } & \multicolumn{2}{c}{ VBP } \\
\cline { 2 - 3 } & $\mathbf{2 0 1 7}$ & $\mathbf{2 0 1 8}$ \\
\hline Soja & 40.824 & 31.339 \\
Açúcar & 16.063 & 11.814 \\
Milho & 18.604 & 11.681 \\
Café & 6.209 & 6.146 \\
Algodão & 4.102 & 3.953 \\
Banana & 4.296 & 3.291 \\
Feijão & 3.884 & 2.777 \\
\hline
\end{tabular}

Fonte: Elaboração própria com base nos dados da Faostat (2021).

Analisando mundialmente, a Tabela 5 apresenta as 10 maiores produções brutas de feijão em milhões de dólares. A Índia aparece em primeira colocação seguida pelo Brasil, os 10 maiores produtores apresentam apenas $24,14 \%$ do valor da produção bruta mundial, o que dá indícios de não haver uma concentração de mercado concedível.

Tabela 5 - Produção bruta dos 10 maiores produtores de feijão do mundo (milhões US\$)

\begin{tabular}{lccccccccc}
\hline \multicolumn{1}{c}{ País } & $\mathbf{2 0 1 0}$ & $\mathbf{2 0 1 1}$ & $\mathbf{2 0 1 2}$ & $\mathbf{2 0 1 3}$ & $\mathbf{2 0 1 4}$ & $\mathbf{2 0 1 5}$ & $\mathbf{2 0 1 6}$ & $\mathbf{2 0 1 7}$ & $\mathbf{2 0 1 8}$ \\
Índia & $3.130,2$ & $2.961,4$ & $2.437,1$ & $2.273,1$ & $2.489,3$ & $2.528,8$ & $3.491,9$ & $4.066,5$ & $3.787,8$ \\
Brasil & $3.089,9$ & $3.475,8$ & $3.701,5$ & $3.727,4$ & $3.261,3$ & $2.354,4$ & $3.228,4$ & $3.883,9$ & $2.776,8$ \\
Estados Unidos & 890,0 & 837,2 & $1.213,5$ & 960,9 & 933,7 & 822,5 & 838,5 & 960,8 & $1.005,0$ \\
Quênia & 246,1 & 403,2 & 469,6 & 511,2 & 531,9 & 602,5 & 542,0 & 774,1 & 737,0 \\
México & 804,1 & 554,6 & $1.046,7$ & $1.004,7$ & 834,7 & 597,5 & 711,1 & 865,2 & 696,6 \\
Irá & 172,7 & 236,3 & 394,2 & 468,8 & 301,3 & 275,6 & 362,3 & 350,5 & 371,1 \\
Camarões & 268,2 & 312,5 & 291,1 & 324,5 & 328,6 & 254,0 & 276,3 & 301,4 & 328,8 \\
Etiópia & 101,8 & 139,3 & 272,5 & 193,3 & 188,3 & 268,6 & 315,5 & 311,6 & 308,7 \\
Japão & 421,4 & 407,6 & 524,4 & 418,4 & 447,6 & 379,5 & 170,8 & 347,1 & 266,2 \\
\hline Vietnã & 127,3 & 134,6 & 139,1 & 223,5 & 233,2 & 234,7 & 213,6 & 237,8 & 261,9 \\
\hline
\end{tabular}

Fonte: Elaboração própria com base nos dados da Faostat (2021).

A Tabela 6 apresentam os 10 maiores exportadores do feijão no mundo. Em 2019, $77,1 \%$ das exportações mundiais foram realizados por esses 10 países, estando em primeiro lugar o Mianmar com 18,28\% das exportações totais, seguido pela China, o Brasil aparece em $9^{\circ}$ lugar com a participação de $2,14 \%$ nas exportações totais.

Tabela 6 - Os 10 maiores exportadores de feijão do mundo (milhões US\$)

\begin{tabular}{cccccccccc}
\hline País & $\mathbf{2 0 1 0}$ & $\mathbf{2 0 1 1}$ & $\mathbf{2 0 1 2}$ & $\mathbf{2 0 1 3}$ & $\mathbf{2 0 1 4}$ & $\mathbf{2 0 1 5}$ & $\mathbf{2 0 1 7}$ & $\mathbf{2 0 1 8}$ & $\mathbf{2 0 1 9}$ \\
\hline Mianmar & 1.000 .000 & 1.500 .000 & 1.300 .000 & 1.050 .000 & 757.079 & 1.060 .779 & 764.932 & 568.727 & 764.367 \\
China & 794.809 & 896.748 & 968.568 & 966.102 & 735.662 & 596.751 & 566.846 & 515.233 & 464.666 \\
China, & 792.799 & 894.909 & 966.206 & 964.327 & 733.878 & 594.472 & 565.244 & 513.591 & 463.074 \\
Continental & & & & & & & & & \\
Estados Unidos & 319.831 & 299.474 & 424.733 & 411.367 & 407.111 & 356.948 & 428.981 & 388.893 & 393.715 \\
Argentina & 259.877 & 328.070 & 362.475 & 118.111 & 290.710 & 273.904 & 316.424 & 289.495 & 380.337 \\
Canadá & 237.946 & 214.073 & 306.680 & 328.942 & 322.894 & 285.461 & 307.510 & 306.321 & 306.024 \\
Uzbequistão & - & - & - & - & 28.355 & 20.706 & 62.093 & 137.022 & 166.127 \\
Turquia & 2.551 & 2.038 & 2.562 & 5.399 & 15.522 & 5.437 & 6.421 & 25.272 & 115.942 \\
Brasil & 4.167 & 21.034 & 31.084 & 23.145 & 45.246 & 76.724 & 76.104 & 72.043 & 89.451 \\
\hline
\end{tabular}

Fonte: Elaboração própria com base nos dados da Faostat (2021).

Os 10 maiores importadores de feijão estão apresentados na Tabela 7, eles representam 45,94\% das importações totais do mundo em 2019. O maior importador é a Índia 
com $11,24 \%$ do total, seguido pelo Japão e Estados Unidos, o Brasil aparece em $10^{\circ}$ lugar com a participação de $2,84 \%$ das importações mundiais de feijão.

Tabela 7 - Os 10 maiores importadores de feijão do mundo (milhões US\$)

\begin{tabular}{|c|c|c|c|c|c|c|c|c|c|}
\hline País & 2010 & 2011 & 2012 & 2013 & 2014 & 2015 & 2017 & 2018 & 2019 \\
\hline Índia & 549.240 & 567.498 & 594.525 & 667.565 & 754.752 & 845.571 & 509.441 & 382.366 & 377.189 \\
\hline Japão & 151.484 & 216.112 & 175.534 & 155.938 & 185.518 & 183.862 & 180.665 & 169.938 & 167.050 \\
\hline Estados Unidos & 156.583 & 197.710 & 205.512 & 176.824 & 183.002 & 207.679 & 180.236 & 160.877 & 153.146 \\
\hline Itália & 113.178 & 136.095 & 153.003 & 183.050 & 225.296 & 162.006 & 137.450 & 153.942 & 146.015 \\
\hline China & 93.449 & 66.958 & 65.334 & 55.536 & 68.313 & 99.678 & 81.481 & 118.532 & 142.986 \\
\hline Turquia & 39.761 & 36.530 & 34.017 & 34.105 & 87.650 & 40.537 & 50.447 & 42.421 & 134.214 \\
\hline Reino Unido & 135.309 & 140.397 & 130.253 & 129.495 & 146.494 & 136.899 & 121.498 & 108.665 & 115.438 \\
\hline $\begin{array}{c}\text { China, } \\
\text { Continental }\end{array}$ & 61.387 & 20.427 & 30.726 & 19.553 & 29.954 & 56.319 & 40.615 & 84.248 & 105.027 \\
\hline México & 113.187 & 102.567 & 284.399 & 140.715 & 87.590 & 84.285 & 134.964 & 139.158 & 104.906 \\
\hline Brasil & 135.004 & 148.348 & 256.881 & 285.211 & 115.564 & 84.808 & 100.061 & 49.482 & 95.257 \\
\hline
\end{tabular}

A partir dos dados apresentados, conclui-se que o mercado físico brasileiro de feijão é grande o suficiente para sustentar um mercado futuro. Porém o Brasil possui uma participação pequena nas importações e exportações mundiais, sendo favorável um aumento do fluxo comercial com outros países para os produtores e demais agentes da cadeia não sejam reféns do consumo interno.

\section{d) Grau de concentração no mercado}

O sistema agroindustrial do feijão é representado basicamente por produtores e beneficiadores, além de fornecedores de insumos, distribuidores atacadistas, varejistas e o consumidor final. Além dos indícios de não haver concentração de mercado, com os os 10 maiores produtores apresentam apenas $24,14 \%$ do valor da produção bruta mundial (Tabela 5), os dados do Censo Demográfico de 2006 apontam um total de 1.360.684 estabelecimentos, sendo estes os principais e mais numerosos agentes do sistema, sendo que destes, 152.748, ou seja $11,22 \%$, são estabelecimentos são familiares.

Os dados da Tabela 8 mostram que o Paraná é o maior produtor de feijão do país com 20,75\%, seguido de Minas Gerais (18,43\%), Goiás (11,73\%), Mato Grosso (9,60\%), São Paulo $(9,11 \%)$ e Bahia $(6,18 \%)$, sendo estes seis estados considerados os maiores produtores de feijão no Brasil. Juntos, eles correspondem a 75,8\% de toda a produção brasileira.

Tabela 8 - Quantidade produzida de feijão por estado no ano de 2019.

\begin{tabular}{ccc}
\hline Estado & Quantidade Produzida $(\mathrm{t})$ & Participação $(\%)$ \\
\hline Brasil & 2.906 .508 & $100 \%$ \\
Paraná & 603.026 & $20,75 \%$ \\
Minas Gerais & 535.744 & $18,43 \%$ \\
Goiás & 341.045 & $11,73 \%$ \\
Mato Grosso & 278.957 & $9,60 \%$ \\
São Paulo & 264.859 & $9,11 \%$ \\
Outros estados & 2.629 .102 & $30,38 \%$ \\
\hline
\end{tabular}

Fonte: Elaboração própria com base em IBGE - Produção Agrícola Municipal (2021).

Os dados da Tabela 9 mostram os dez maiores municípios produtores do país, Paracatu no estado de Minas Gerais apresenta a maior participação $(2,92 \%)$ da produção brasileira, seguido de Sorriso-MT (2,57\%) e Nova Ubiratã-MT (2,06\%). Todavia, deve se destacar que 


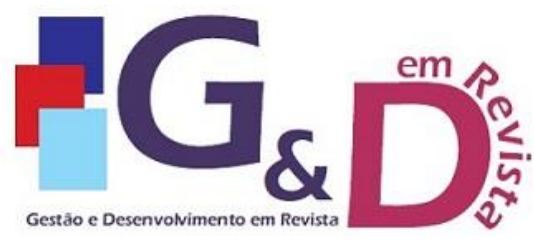

Gestão e Desenvolvimento em Revista

V. 8, N. 2, jul-dez/2021, p. 22-41.

ISSN online: $2446-8738$

Artigo recebido em: 08/11/2021

Artigo aprovado em: 08/12/2021

no aspecto geral as variações entre os municípios não apresentam uma diferença significativa quanto a sua participação.

Tabela 9 - As 10 maiores cidades produtoras de feijão do Brasil no ano de 2019.

\begin{tabular}{lcc}
\hline \multicolumn{1}{c}{ Município } & Quantidade Produzida (t) & Participação \% \\
\hline Paracatu (MG) & 84.870 & $2,92 \%$ \\
Sorriso (MT) & 74.736 & $2,57 \%$ \\
Nova Ubiratã (MT) & 59.970 & $2,06 \%$ \\
Unaí (MG) & 55.200 & $1,90 \%$ \\
Cristalina (GO) & 47.160 & $1,62 \%$ \\
Paranapanema (SP) & 38.100 & $1,31 \%$ \\
Prudentópolis (PR) & 36.302 & $1,25 \%$ \\
Itapeva (SP) & 35.000 & $1,20 \%$ \\
Brasília (DF) & 33.609 & $1,16 \%$ \\
Guarda-Mor (MG) & 32.400 & $1,11 \%$ \\
\hline
\end{tabular}

Fonte: Elaboração própria com base em IBGE - Produção Agrícola Municipal (2021).

Embora possa se apresentar uma certa predominância em certos estados não se verifica uma produção espacialmente concentrada e nem grandes produções, se aproximando o setor produtivo, dessa forma, da competição perfeita. Ou seja, nenhum produtor sozinho consegue influenciar o preço do mercado, além de o mercado ser bastante pulverizado e o produto ser de fácil padronização.

\section{e) Intervenção governamental}

A cultura do feijão tem intervenção governamental principalmente pela Companhia Nacional de Abastecimento (CONAB), a qual tem como missão contribuir para a regularidade do abastecimento e garantia de renda ao produtor rural, participando da formulação e execução das políticas agrícolas e de abastecimento. Em obediência às questões legais, a CONAB pode adquirir produtos com amparo da Política de Garantia de Preços Mínimos (PGPM) e do Programa de Aquisição de Alimentos (PAA) e que estejam enquadrados nos padrões oficiais de classificação (OLIVEIRA NETO; SANTOS, 2018)

Quanto a Política de Garantia de Preços Mínimos (PGPM), o governo estabelece um valor mínimo ao produto com intuito de garantir a oferta de alimentos à sociedade, sendo que por meio desse preço mínimo é definida a base dos valores recebidos pelos produtores. $\mathrm{O}$ valor é determinado antes do início do plantio e, dessa forma, o agricultor tem uma melhor previsão quanto a forma de alocar os seus recursos, bem como o tipo de cultura que será produzida durante o ano. (SANCHES; BACHA, 2015).

O feijão faz parte da Política de Garantia de Preços Mínimos (PGPM). Para essa cultura há diferentes de instrumentos ${ }^{2}$ e apoio à comercialização e garantia de preços mínimo, dentre os quais cabe destacar: Aquisições do Governo Federal (AGF), Contrato de Opção de Venda de Produtos Agropecuários (COV), Financiamento para Estocagem de Produtos Agropecuários integrantes da Política de Garantia de Preços Mínimos (FEPM), Financiamento para Garantia de Preços ao Produtor (FGPP), Prêmio para o Escoamento de Produto (PEP), Prêmio Equalizador Pago ao Produtor (PEPRO), Prêmio de Risco para Aquisição de Produto Agrícola Oriundo de Contrato Privado de Opção de Venda (PROP), Valor para Escoamento do Produto (VEP) e leilões públicos.

\footnotetext{
${ }^{2}$ Por brevidade citou-se apenas os tipos de instrumentos. Informações complementares podem ser obtidas na Companhia de Nacional de Abastecimento (CONAB).
} 
Por sua vez, cabe destacar também o PAA, compra alimentos produzidos pela agricultura familiar, com dispensa de licitação fomentando o desenvolvimento da agricultura familiar brasileira. Segundo Assunção e Wander (2015), a política de aquisição de alimentos influencia de maneira direta a formação de preços e nos mecanismos de comercialização que podem ser adotados pelos produtores de feijão. Essa política de incentivo à comercialização agrícola visa diminuir a sazonalidade da produção rural.

A safra da seca, aquela normalmente plantada entre janeiro e março e colhida entre abril e julho, devido à sua expressiva abrangência geográfica, possui uma alta variabilidade de épocas de plantio, as quais dependem do grau de disponibilidade de água para suprir as necessidades das plantas nas diversas fases de desenvolvimento. A importância e o alto risco dessa safra fizeram com que o governo, por meio de seus órgãos competentes, promovesse um programa de zoneamento agroclimático para a cultura do feijão da seca, nos principais estados e regiões produtoras do País (EMBRAPA ARROZ E FEIJ ÃO, 2004).

Como dito anteriormente, o feijão detém características fisioquímicas que não permitem o seu armazenamento por longos períodos, pois em pouco tempo perde umidade, escurece e suas propriedades organolépticas são comprometidas. Sendo assim, a preocupação com relação à intervenção do governo no mercado é que normalmente o produto adquirido foge do seu principal atributo (cor) e fica armazenado por longos períodos. Nota-se que, mesmo quando são colocados à venda, a preços bem abaixo dos praticados no mercado, são raras as perspectivas de comercialização.

No sentido de viabilizar as vendas dos estoques, o governo se ampara nos critérios estabelecidos nas portarias interministeriais $\mathrm{n}^{\circ} \mathrm{s} 224$ e 454 , ambas de 4 de novembro de 1997 , tomando como parâmetro os preços médios de mercado de um produto similar, na região de depósito, sobre o qual se aplicam os deságios para comercialização de acordo com o tempo de estocagem em relação à safra vigente e, caso não tenha êxito, são submetidos a carta convite. (CONAB, 2008)

De acordo com a CONAB (2008) a presença do governo é imprescindível para a tomada de decisões do produtor. O baixo uso de tecnologia, a necessidade hídrica e a suscetibilidade a pragas e doenças são alguns dos fatores que fazem do feijão uma cultura de risco. Por isso, em alguns anos, a produção é alta e, em outras, há quebras de safras. $\mathrm{O}$ mercado de feijão apresenta fortes oscilações de preços entre anos.

Além disso, a falta de um mercado internacional e a perecibilidade do produto tornam difícil estimar a estacionalidade e fazer projeções baseando-se em dados históricos do produto. Em quebra de safra ocorre muita especulação e elevação do preço, enquanto em época de superprodução o preço despenca, sendo necessária a intervenção do governo. Entretanto, ressalta-se que a demanda interna de feijão é basicamente estática (FUSCALDI, 2005).

\section{f) Formas de comercialização}

O fato de a produção ser concentrada no tipo carioca (63\%) é considerado um entrave na comercialização do produto, pois o Brasil é considerado o único produtor e consumidor dessa variedade no mundo, devido a sua alta taxa de deterioração é pouco aceito no mundo. Quando há alguma quebra na safra, esse problema se agrava ainda mais, uma vez que a oferta do produto se torna escassa. No caso de um excesso de oferta, é inviável a exportação do produto pois, como vimos, não é aceito no exterior, sendo que dessa forma o produto fica escurecendo nos armazéns, perdendo qualidade e onerando custos de carregamento, gerando deságio na venda (BRASIL, 2018).

Como visto na seção de volatilidade de preços, o preço do feijão no Brasil é volátil, dificultando o planejamento por parte dos agentes da cadeia. Contudo, cabe destacar que na 
cadeia produtiva do feijão-comum, a coordenação por meio de contratos é mais difícil de serem desenvolvidos, pois muitos produtores não apresentam conhecimento do funcionamento desse processo e, por estar há muitos anos atuando na cadeia produtiva do feijão-comum, apresentam receios grandes em relação a qualquer atitude e ação que fujam do que eles conhecem ou tem costume de ver durante a comercialização (ASSUNÇÃO e WANDER, 2015).

Segundo Wander (2005), a comercialização é a mais variada possível, com predomínio de um pequeno grupo de atacadistas que concentra a distribuição da produção, gerando por muitas vezes, especulações quando ocorrem problemas na produção, onde, os canais de comercialização do feijão variam de acordo com cada região, envolvendo diferentes agentes comerciais (ou intermediários), agroindústrias e serviços que demandam diferentes infraestruturas de apoio (logística).

Segundo Assunção e Wander (2015) os atacadistas são agentes intermediários no processo de distribuição, em relação ao produtor/agroindústria/consumidor final. A venda para o intermediário é uma garantia de mercado para os produtores de feijão que não coordenam sua produção por contratos a termo e, em alguns casos, os intermediários podem ficar com o todo o lucro inerente à fase de produção. Spers e Nassar (1998) argumentaram que os intermediários são figuras frequentes e podem ser colocados como atores ativos dentro dos canais de comercialização e distribuição de feijão.

Os varejistas, ainda segundo Assunção e Wander (2015) são representados pela agroindústria. A agroindústria busca fazer a fixação de preços em contrato a termo, pois isso evitar que a agroindústria tivesse que pagar um alto preço pelo feijão. A compra tende a ser centralizada, exigindo dos fornecedores entrega em escala e em dias prefixados e as agroindústrias buscam ter a rastreabilidade do produto, exigindo condições de tratamentos fitossanitários que respeitem o tempo da agroindústria e evitem resíduos de defensivos no processamento do produto final.

O mercado de contratos a termo ainda não é totalmente aderido. Em muitos casos, é preciso ainda procurar um centro onde será comercializado o feijão-comum produzido, tornando ineficiente o processo de comercialização. Apenas algumas agroindústrias tentam a coordenação por contratos, mas nem todos os produtores fornecedores dessas agroindústrias participam de tal coordenação. Cabe destacar também que o elo da agroindústria é muito importante para a comercialização de feijão-comum. Segundo esse elo, cerca de $85 \%$ do feijão comercializado no Brasil apresenta passagem pela agroindústria (ASSUNÇÃO e WANDER, 2015).

\section{g) Volatilidade}

O mercado de feijão sofre algumas influências, sendo elas principalmente pelo tipo do grão que é comercializado, fatores agronômicos e sazonalidades, sendo que o preço depende muito mais do mercado interno. Cabe lembrar também que o preço pode ser influenciado pela existência de três safras facilitando a mudança na intenção de plantio.

Para o cálculo da volatilidade dos preços, foram utilizados os preços mensais dos estados do Paraná, Minas Gerais e Goiás, maiores produtores de feijão do país, além de São Paulo e Bahia, uma vez que, segundo Coelho (2019), o mercado atacadista de São Paulo e, no Nordeste, a de Barreiras-BA são importantes da formação dos preços. Por fim, Borém e Carneiro (2006) afirmam que os estados de mais representatividade produtiva de feijão comum são Paraná, Minas Gerais, São Paulo, Goiás e Bahia.

A Tabela 10 apresenta o resultado do cálculo da volatilidade, feito conforme a equação 1, entre janeiro de 2016 e dezembro de 2020 para os estados citados. 
Tabela 10 - Volatilidade do preço do feijão comum em cores para os estados do Paraná, Minas Gerais, Goiás, São Paulo e Bahia, no período entre janeiro de 2016 a dezembro de 2020.

\begin{tabular}{cc}
\hline Estado & Volatilidade \\
\hline Paraná & $20,10 \%$ \\
Minas Gerais & $21,68 \%$ \\
Goiás & $20,11 \%$ \\
São Paulo & $19,24 \%$ \\
Bahia & $21,40 \%$ \\
\hline
\end{tabular}

Fonte: Elaborado pelo autor com base de dados do CEPEA (2021).

Os dados mostram que o preço do feijão apresentou elevada volatilidade no período analisado, sendo o estado de Minas Gerais o de maior volatilidade e o estado de São Paulo o menor. Cabe destacar que essa alta volatilidade vai de encontro ao esperado e dá sustentação a possibilidade da existência de um contrato futuro. Para uma melhor compreensão quanto a este aspecto, o gráfico abaixo apresenta a variação dos preços nos estados analisados.

Gráfico 1 - Preços nominal mensal do feijão comum em cores nos estados do Paraná, Minas Gerais, Goiás, São Paulo e Bahia no período entre janeiro de 2016 e dezembro de 2020.

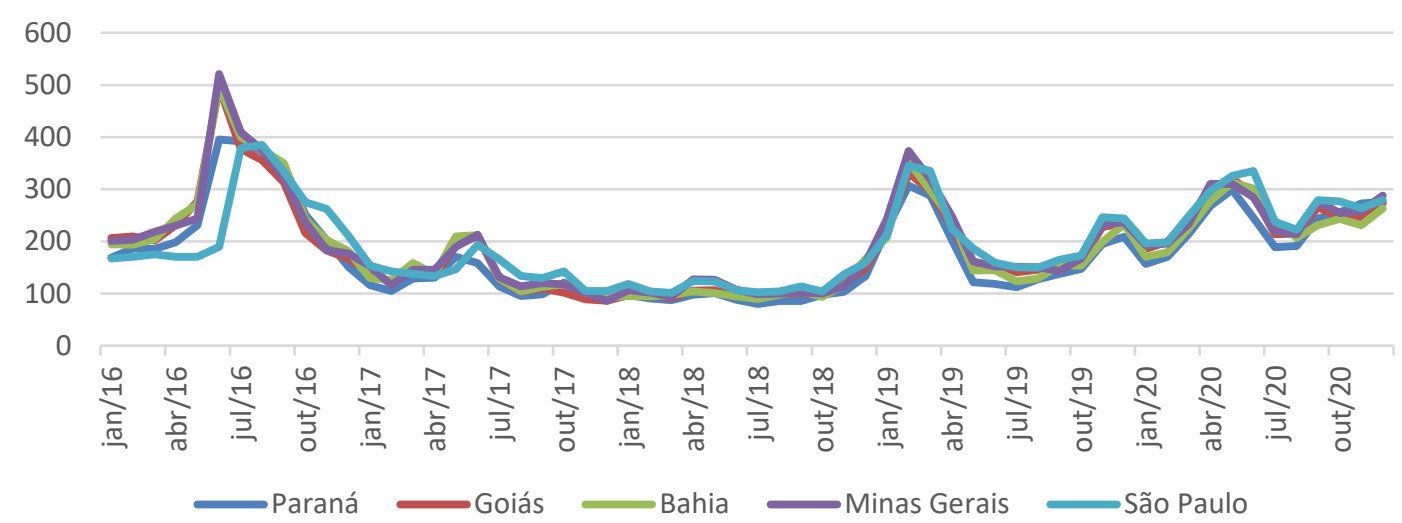

Fonte: Elaborado pelo autor com base de dados do CEPEA (2021).

Através do gráfico 1, percebe-se que os preços variaram muito no período analisado. Os estados da Bahia e de Minas Gerais tiveram os maiores preços da série em junho de 2016. Já o menor preço observado foi no estado do Paraná no mês de julho de 2018 onde chegou a 79,89 a saca. Como se vê, há picos e vales na série, o que é comum no setor agrícola, uma vez que os produtores aumentam a produção em momentos de melhores preços, elevando a oferta.

Além de verificar as volatilidades, torna-se importante comparar elas com a dos produtos que possuem contratos futuros na bolsa de mercadorias e futuros (B3) com o objetivo de verificar se o nível de volatilidade observado é suficiente para atrair agentes da cadeia feijoeira para o mercado futuro. Sendo assim, a tabela 11 apresenta a volatilidade do feijão juntamente com outras commodities que são negociadas na B3. 


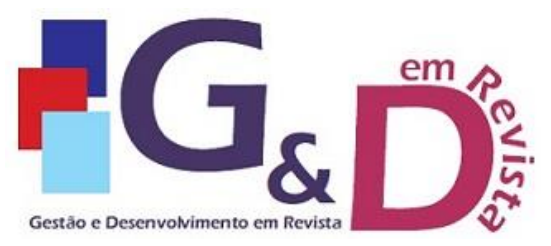

Gestão e Desenvolvimento em Revista

V. 8, N. 2, jul-dez/2021, p. 22-41.

ISSN online: $2446-8738$

Artigo recebido em: 08/11/2021

Artigo aprovado em: 08/12/2021

Tabela 11 - Volatilidade das commodities negociadas na B3, no período entre janeiro de 2016 e dezembro de 2020.

\begin{tabular}{cc}
\hline Estado & Volatilidade \\
\hline Soja & $5,13 \%$ \\
Milho & $7,21 \%$ \\
Boi Gordo & $4,27 \%$ \\
Café Arábica & $5,57 \%$ \\
Cana de Açucar & $2,49 \%$ \\
Açucar Cristal & $6,19 \%$ \\
Etanol Hidratado & $8,56 \%$ \\
Etanol Anidro & $8,28 \%$ \\
\hline
\end{tabular}

Fonte: Elaborado pelo autor com base de dados do CEPEA (2021).

A Tabela 11 mostra que a volatilidade dos produtos comercializados na B3 é menor do que a do feijão. Essa comparação demonstra que o produtor de feijão necessita buscar novos mecanismos de proteção, a fïm de diminuir sua exposição aos riscos de oscilações de preços. Portanto, conclui-se que a volatilidade dos preços para o feijão é significativa, sendo um aspecto positivo para a implantação de um mercado futuro no país.

\section{h) Integração Vertical}

O feijão tem uma ampla adaptação edafoclimática o que permite seu cultivo, durante todo o ano, em quase todas os estados da federação, possibilitando constante oferta do produto no mercado. Outra característica desta leguminosa é possibilitar a sua produção em diversos ecossistemas tropicais e temperados, em monocultivo ou consorciado nos mais variados arranjos de plantas inter e intraespecíficos, o que favorece a diversificação na produção, mas limita uma maior integração na sua cadeia produtiva (OZON, 2002)

É considerado uma cultura de subsistência em pequenas propriedades, adotada também em sistemas de produção que requerem o uso de tecnologias intensivas como a irrigação, controle fitossanitário e colheita mecanizada (SEAB, 2019). No gráfico 2 apresentase a porcentagem do número de estabelecimentos agropecuários produtores de feijão em cor que são integrados. Pode-se ver que 56\% são pouco integrados, $32 \%$ integrados e apenas $12 \%$ muito integrados. Os valores muito próximos ao do milho em grão, produto que já possui contrato futuro na B3.

Gráfico 2 - Porcentagem de a porcentagem de número de estabelecimentos agropecuários produtores de feijão em cor que são integrados.

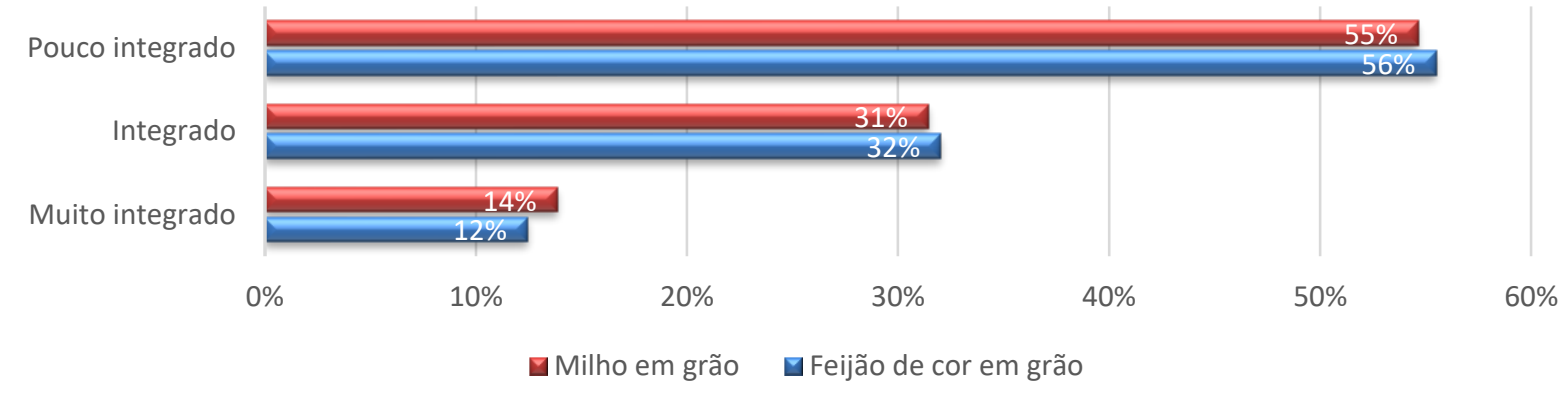

Fonte: Elaboração própria com base de dados do IBGE (2021). 
Então, haja vista que no Brasil o feijão é considerado uma cultura que se predomina em pequenas propriedades e que a grande maioria dos estabelecimentos são pouco integrados, conclui-se que não há indícios de uma considerável integração vertical no setor, o que demostra que ela não é um empecilho para a implantação do contrato futuro de arroz no país.

\subsection{VIABILIDADE DE IMPLANTAÇÃO DO CONTRATO FUTURO}

$\mathrm{Na}$ abordagem macro, foram verificadas as variáveis relevantes para a implantação do contrato futuro de feijão no Brasil. Dos oito aspectos analisados, quatro apresentam situações favoráveis e as outras quatro, desfavoráveis. O sinal esperado é ditado conforme feito por Aguiar (2003). A Tabela 12 apresenta os sinais esperados e os encontrados para cada variável estudada.

Tabela 12- Sinais encontrados para as variáveis que influenciam no sucesso dos contratos futuros

\begin{tabular}{lcc}
\hline \multicolumn{1}{c}{ Característica } & Sinal Esperado & Sinal Encontrado \\
\hline Perecibilidade e possibilidade de estocagem & + & - \\
Homogeneidade e capacidade de mensuração & + & - \\
Volatilidade do preço & + & + \\
Tamanho do mercado físico & + & + \\
Grau de concentração no mercado & - & - \\
Formas de comercialização & - & + \\
Intervenção governamental & - & + \\
Integração vertical & - & - \\
\hline Fon Resura
\end{tabular}

Fonte: Resultados da pesquisa.

A perecibilidade e possibilidade de estocagem mostrou-se desfavorável, pois apesar do produto ser considerado não perecível vários fatores podem alterar a qualidade do feijão. Não é homogêneo, tendo diversas variedades, porém o MAPA possui uma classificação onde é possível realizar a catalogação do produto o que amenizar a heterogeneidade, mas não resolve o problema.

O tamanho do mercado físico mostrou-se favorável, pois o Brasil está entre os 10 países que mais comercializam feijão, tendo também um amplo mercado interno desta mercadoria, em especial para o feijão carioca, um tipo de feijão comum, que representa $63 \%$ da produção total. $O$ grau de concentração do mercado também se apresentou favorável por evidenciar um mercado de pequenos produtores e bem distribuído entre os estados brasileiros.

A intervenção governamental mostrou-se desfavorável com diversas intervenções governamentais ao longo dos anos, impactando em muitos momentos no preço do produto. Já quanto as formas de comercialização têm-se verificado que as agroindústrias se utilizam de contratos a termo, já os feijoeiros utilizam em escala menor e sofrem uma certa rejeição por parte dos produtores por falta de informação, mostrando assim desfavorável para a utilização de contratos futuros.

Com relação a volatilidade, os preços se mostram bastante voláteis, sendo influenciados por fatores climáticos e sazonais, sendo considerado um ponto favorável a realização de contratos futuros. Todavia, há de destacar o papel governamental nesse aspecto com a política de preços mínimos. Por fim, os estabelecimentos agropecuários produtores de feijão mostraram-se pouco integrados, sendo mais um ponto positivo para a implementação do contrato futuro. 
Dessa forma, conclui-se que embora alguns aspectos sejam favoráveis a execução de um contrato futuro, entre estes os preços serem voláteis o que é considerado o principal ponto para garantir uma melhor segurança para os agentes envolvidos, não se verifica a viabilidade do contrato futuro para o feijão comum no Brasil, uma vez que o produto pode ser perecível, dificultando sua estocagem por longos períodos e não é homogêneo, o que traria a necessidade de contratos com designs diversos. Além disso, o setor possui alta intervenção governamental, com políticas de preços mínimos. Os agentes desse mercado já atuam com contratos a termo, o que proporciona riscos menores para produtores e agroindústrias. Sendo assim, não se torna necessário estabelecer um design para o contrato.

\section{CONSIDERAÇÕES FINAIS}

O presente estudo teve como objetivo analisar a viabilidade da estruturação de um mercado futuro de feijão comum no Brasil. Para isso, utilizou-se a metodologia de Pennings e Leuthold (1999) os quais classificaram como macro e micro os determinantes da viabilidade dos contratos futuros. $\mathrm{O}$ estudo focou na abordagem macro, que leva em conta os fatores não subjetivos ou os conjuntos de atributos físicos que a commodities deve possuir para um possível sucesso deste contrato futuro.

Mais precisamente analisou-se a perecibilidade e possibilidade de estocagem do feijão, se o produto é homogêneo e passível de mensuração, qual o tamanho do mercado de feijão no Brasil e se este mercado é concentrado ou não. Além disso, verificou-se também o papel no governo, as formas de negociações, a volatilidade dos preços e por fim a integração vertical do mercado.

Após as análises verificou-se pontos favoráveis e desfavoráveis para a realização do contrato futuro de feijão. Quanto ao tamanho do mercado físico, destacou-se que o Brasil está entre os 10 países que mais comercializam feijão, tendo também um amplo mercado interno desta mercadoria, em especial para o feijão carioca que representa $63 \%$ da produção total, o grau de concentração do mercado evidencia um mercado de pequenos produtores e bem distribuído entre os estados brasileiros, sendo estes estabelecimentos integrados entre si.

Quanto aos aspectos favoráveis, os preços do feijão são voláteis, apresentando inclusive volatilidade bem superior as commodities que possuem que já possuem contratos futuros na bolsa. Cabe lembrar que a volatilidade é considerada como principal fator para a possibilidade de um contrato futuro.

Todavia, todos os demais pontos se mostraram desfavoráveis, concluindo se assim a não viabilidade do contrato futuro de feijão no Brasil. Apesar do produto ser considerado não perecível vários fatores podem alterar a qualidade do feijão, tornando difícil sua estocagem e, além disso, o produto não é homogêneo. Além disso, embora os preços sejam voláteis, há diversas intervenções governamentais no mercado de feijão, sendo a principal a política de preços mínimos, impactando diretamente no preço do produto. Por fim, tem se verificado a utilização de contratos a termo pelas agroindústrias os quais tem se mostrado satisfatórios proporcionando riscos menores para produtores e agroindústrias e, além disso, o próprio governo atua como um concorrente para o mercado futuro quando utiliza instrumentos que asseguram ao produtor preços mínimos e compras de sua produção, sendo, portanto, um concorrente para o mercado futuro.

É importante mencionar que os produtores de feijão devem assumir uma postura empresarial porque a nova realidade exige culturas conduzidas mediante o uso da irrigação e alto nível tecnológico, além de um cuidadoso planejamento, principalmente na comercialização, a combinação desses fatores torna possível o controle da produção. 


\section{REFERÊNCIAS BIBLIOGRÁFICAS}

AGUIAR, D. R. D.; SANTOS, A. H. G. Análise dos Fatores Determinantes da Viabilidade de Implantação do Contrato Futuro de Suínos Vivos no Brasil. Revista de Economia do Agronegócio, v. 1, n. 2, p. 231-256, 2003.

ASSUNÇÃO, P. E. V.; WANDER, A. E. Análise dos tipos de comercialização de feijãocomum no Estado de Goiás. Informações Econômicas, São Paulo, v. 45, n. 1, p. 35-47, jan./fev. 2015.

BIAVA, M; MOREIRA, J. A. A.; STONE, L. F. Feijão, o produtor pergunta, a Embrapa responde. Coleção 500 perguntas, 500 respostas. Brasília, DF: Embrapa Informação Tecnológica, 2003.

BLACK, D. G. Success and Failure of Futures Contracts: theory and empirical evidence. Monograph Series in Finance and Economics. New York, NY: Salomon Brothers Center for the Study of Financials Institutions, c 1986.

BRAGANTINI, C. Alguns aspectos do Armazenamento de Sementes e Grãos de Feijão. Embrapa Arroz e Feijão, Santo Antônio de Goiás - GO, ISSN 1678-9644, 2005. Disponível em: < https://www.infoteca.cnptia.embrapa.br/bitstream/doc/194008/1/doc187.pdf $>$. Acesso em: 06, jan. 2021.

BRASIL. CVM. Mercado Futuro. Disponível em: 〈https://www.investidor.gov.br >. Acesso em: 18 mar. 2021.

BRASIL. Ministério da Agricultura, Pecuária e Abastecimento. Instrumentos de Política Agrícola. Brasília, DF, 2017. Disponível: 〈https://www.conab.gov.br/precosminimos/instrumentos-de-policia-agricola\#fepm>. Acesso em: 18, jan. 2021.

BRASIL. Ministério da Agricultura, Pecuária e Abastecimento. Instrução Normativa 12/2008. Brasília, DF, 2008. Disponível: 〈https://www.gov.br/agricultura >. Acesso em: 18, jan, 2021.

BRASIL. Ministério da Agricultura, Pecuária e Abastecimento. Secretária Executiva. Plano Nacional para o Desenvolvimento da Cadeia Produtiva do Feijão e Pulses. Brasília, DF, 2018. Disponível: <https://www.gov.br/agricultura/ >. Acesso em: 18, jan. 2021.

BRORSEN, B.W.; FOFANA, N.F. Success and failure of agricultural futures contracts. Journal of Agribusiness, Athens, v.19, n.2, p.129-145, 1995.

BRENNAN, M. J. The Supply of storage. The American Economic Review, v. 48, n. 1, p.5072, 1958.

BORÉM, A.; CARNEIRO, J. E. S. A cultura. In: VIEIRA, C.; PAULA JÚNIOR, T. J.; BORÉM, A. Feijão. 2. ed. atual. e ampl. Viçosa, MG: Ed. UFV, 2006. p. 13-18.

COÊLHO, J. D. Produção de grãos - Feijão, milho e soja. n.41. Fortaleza: Caderno setorial Etene, 2019. 
COMPANHIA NACIONAL DE ABASTECIMENTO. A Cultura do Feijão. P. 244, ISBN: 978-85-62223-12-9, 2018.

COMPANHIA NACIONAL DE ABASTECIMENTO. Compêndio de Estudos Conab. Agricultura Familiar Programa de Aquisição de Alimentos - PAA: Resultados das Ações da Conab em 2019. V. 27, ISSN: 2448-3710, Brasília, DF, 2020.

COMPANHIA NACIONAL DE ABASTECIMENTO - CONAB. Dados Estatísticos. Brasília, 2020.

COSTA, A. A. Condições para a implantação do contrato futuro de arroz no Brasil. Viçosa, MG: UFV, IMPRENSA Universitária, 2008. 134 f. Dissertação (Mestrado em Economia Rural) - Universidade Federal de Viçosa, Viçosa.

CUNHA, C. F. Microeconomia: teoria, questões e exercícios. São Paulo: Makron Books, 2000.

DALCHIAVON, F. C. et. all. Viabilidade espacial da produtividade do feijoeiro correlacionada com atributos químicos de um Latosso Vermelho Distroférrico sob sistema de semeadura direta. Bragantina, Campinas, SP, v. 70, n. 4, p.908-916, 2011.

DEL PELOSO, M.J.; MELO, L.C. Potencial de rendimento da cultura do feijoeiro-comum. Santo Antônio de Goiás: Embrapa Arroz e Feijão, 2005. 131p.

DURIGNON, M. A. et. all. Estratégias de Comercialização do Feijão no Rio Grande do Sul. Pelotas, RS, INNS 1516-8840, Embrapa, 2015. Disponível:

<https://core.ac.uk/download/pdf/33891257.pdf >.Acesso em: 16,jan,2021.

EMBRAPA ARROZ E FEIJÃO. Disponível em: 〈https:www.embrapa.br/arroz-e-feijao〉. Acesso em: 11.dez. 2020.

FAOSTAT. Food and agriculture data. Disponível em:

<http://www.fao.org/faostat/en/\#home >. Acessado em: 11, jan,2021.

FONSECA, J. R. Beneficiamento e armazenamento do feijão. EMBRAPA, Brasília, DF, 2020. Disponível:

<https://www.agencia.cnptia.embrapa.br/Repositorio/AG01_2_262003151355.html>. Acesso em: 30, nov. 2020.

FUSCALDI, K. C. PRADO, G. R. Análise econômica da cultura do feijão. Revista de Política Agrícola, v. 14, n. 1, p. 17-30, Jan./Mar. 2005. Disponível:

$<$ https://seer.sede.embrapa.br/index.php/RPA/article/viewFile/527/477>. Acesso em: 08, jan. 2021.

PELOSO, M. J. D. SILVA, C. C. Informações técnicas para o cultivo do feijoeiro comum da Região Central-brasileira 2005-2007. Reunião da Comissão técnica Central-brasileira de feijão. Goiânia, GO, ISSN 1678-9644, Embrapa Arroz e Feijão, 2006. Disponível em: <http://docsagencia.cnptia.embrapa.br/feijao/doc_193.pdf>. Acesso em: 06, dez, 2020. 


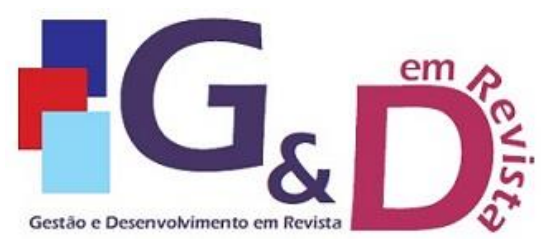

Gestão e Desenvolvimento em Revista V. 8, N. 2, jul-dez/2021, p. 22-41.

ISSN online: $2446-8738$

Artigo recebido em: 08/11/2021

Artigo aprovado em: 08/12/2021

GRANT, R. M. Comtemporary Strategy Analysis: Concepts, Techniques, Applications. $4^{\mathrm{a}}$ Ed. USA: Blackwell Publishers, 2002.

HULL, J. C. Fundamentos dos Mercados Futuros e de Opções. 4. Ed. São Paulo: Bolsa de Mercadorias e Futuros, 2005. 597 p.

IBGE. Instituto Brasileiro de Geografia e Estatística. Disponível em: <http://www.ibge.gov.br>. Acesso em: 22, dez, 2020.

JUBERT, R. W. et. al. Um Estudo do Padrão de Volatilidade dos Principais Índices Financeiros do Bovespa: uma Aplicação de Modelos Arch. Universidade de Brasília Departamento de Ciêncas Contábeis e Atuariais. Revista UnB Contábil, v. 11, n. 1-2, p.221239, jan./dez. 2008. Disponível: https///www.revistacgg.org. Acesso em: 27-nov-2020.

KALDOR, N. Speculation and economic stability. The Review of Economics Studies, v. 7 , n.1, p.1-27,1939.

LIRA, M. C, ALMEIDA, S. A. A volatilidade no mercado financeiro em tempos da pandemia do (novo) coronavírus e da covid-19: Impactos e projeções. Facit Business and Technology Journal. v. 1, n. 19, p.140-157, 2020. Disponível:

http://revistas.faculdadefacit.edu.br/index.php/JNT/article/viewFile/677/499. Acesso em: 18mar-2021.

MARQUES, P.V; MELLO, P. C; MARTINES, J.G. Mercados Futuros e de Opções Agropecuárias. Piracicaba, S.P., Departamento de Economia, Administração e Sociologia da Esalq/USP, 2006.

MILACH, F. T.; JUSTEN JUNIOR, A. A.; VIEIRA, K. M. Mercado Futuro de Açúcar e Álcool: Uma análise sob a ótica da liquidez e da produção física. In: XXVIII Encontro Nacional de Engenharia de Produção. Rio de Janeiro, 2008.

OLIVEIRA NETO, A. A; SANTOS, C. M. R. A cultura do feijão. Brasília: Conab, 2018.

OZON, R. T. Análise da cadeia produtiva do feijão na região de União Da Vitória - PR. Universidade Federal de Uberlândia. Florianópolis, SC, 2002. Disponível em: <https://core.ac.uk/download/pdf/30364477.pdf $>$. Acesso em: 16, jan. 2021.

PELOSO, M. J. D; SILVA, C. C. Informações técnicas para o cultivo do feijoeiro comum da Região Central-brasileira 2005-2007. Reunião da Comissão técnica Central-brasileira de feijão. Goiânia, GO, ISSN 1678-9644, Embrapa Arroz e Feijão, 2006. Disponível em: <http://docsagencia.cnptia.embrapa.br/feijao/doc_193.pdf>. Acesso em: 06, dez, 2020.

PORTER, M. E. Estratégia competitiva. Rio de Janeiro: Ed. Campus, 1986.

PURCELL, W.D.; KOONTZ, S.R. Agricultural futures and options principles and strategies. 2.ed. Upper Saddle River: Prentice Hall, 1999. 
SANCHES. A; BACHA. C. J. C. Políticas de estabilização de preços agrícolas: o de caso do mercado do milho em Mato Grosso. In: Congresso Sociedade Brasileira de Economia, Administração e Sociologia Rural. João Pessoa, 2015.

SANTOS, A.H.G. Potencial de implantação do contrato futuro de suínos no Brasil. 2001. 110p. Dissertação (Mestrado em Economia Rural) - Universidade Federal de Viçosa, Viçosa, 2001.

SECRETARIA DE ESTADO DA AGRICULTURA E DO ABASTECIMENTO - SEAB. Feijão - Análise da Conjuntura Agropecuária. Disponível em:

<http://www.agricultura.pr.gov.br/sites/default/arquivos_restritos/files/documento/201909/feijao_2019_v1.pdf>. Acesso em: 15, jan. 2021.

SIDRA-IBGE. Censo Agropecuário 2006. Tabela 3411. Brasilia, DF, 2007. Disponivel em: <https://sidra.ibge.gov.br/tabela/3411>. Acesso em: 02, jan. 2021.

SILVA, B. A. O. Resultado Econômico da Estocagem no âmbito da cafeicultura brasileira. Universidade Federal de Uberlândia. Uberlândia, MG, 2012. Disponível em:

$<$ http://sbicafe.ufv.br/bitstream/handle/123456789/5898/Dissertacao_Breno\%20Augusto\%20 de\%20Oliveira\%20Silva.pdf?sequence=1\&isAllowed=y >. Acesso em: 06, jan. 2021.

SIQUEIRA, K. B. Viabilidade de Implantação de Contrato Futuro de Leite no Brasil. 109 f. Dissertação (Mestrado em Economia Rural) - Universidade Federal de Viçosa, Viçosa, MG, 2003.

WANDER, A. E.; SILVA, OF da. Cultivo do feijão irrigado na região noroeste de Minas Gerais. Goiás: Embrapa Arroz e Feijão, 2005.

WILLIAMSON, O. E. The Economics Institution of Capitalism - The Free Press. New York, 449p. 1996.

WORKING, H. The theory of price storage. The American Economic Review, v. 39, n. 6, p. 1254-1262, 1949.

1 